\title{
PREDICTIVE VALUE OF MODIFIED SEVERITY INDEX FOR FOURNIER'S GANGRENE
}

\author{
Abdul Samad
}

\begin{abstract}
BACKGROUND/OBJECTIVE: Fournier's gangrene is a rare but lethal disease initiating from minor local infection in the perineal viscera in susceptible individuals. It is the synergistic necrotizing fascitis of the genital, urinary and perianal tissues. The objective of this study was to determine if incorporating the skin loss and platelets count increases the predictive value of fournier's gangrene severity index described by Laor et al.

METHODS: This is an analysis of demographics, presentations, concomitant morbidities, management and outcome in $\mathbf{1 5}$ patients with fournier's gangrene managed during last fifteen years. Various clinical and para-clinical parameters were scored on the basis of Laor's index. The additional features of surface area and platelets count were also scored for the modified index. Then the relationships of these two indices with survival were evaluated.

RESULTS: In this study of 15 patients, the mortality rate was $27 \%$. Regarding Laor's index, the mean score for survived group was 6 with the range of 2 to 10 whereas that for dead group was 11.5 with the range of 8 to 13 . There was $67 \%$ probability of death for the patients scoring more than "7" whereas the score of "7" or less was associated with $100 \%$ probability of survival. Regarding the modified index, the mean score for survived group was 8.5 with the range of 2 to 12 whereas that for dead group was 15 with the range of 14 to 17 . There was $100 \%$ probability of survival for the patients having score of "12" or less whereas the score of more than "12" was associated with $100 \%$ probability of death.

CONCLUSION: The proposed modification of Laor's index appears to be having better predictive value of outcome but needs to be evaluated in trials having statistical significance.
\end{abstract}

KEY WORDS: Fournier's gangrene. Fascitis. Prognosis. Severity index. Scoring system.

\section{INTRODUCTION}

Fournier's gangrene is a rare but extremely devastating condition resulting from local infection in the perineal viscera in susceptible individuals. It is the synergistic necrotizing fascitis of the scrotum or perineum that may extend to the penis, anterior abdominal wall, buttocks or lower extremities. Its cutaneous manifestations are merely the tip of iceberg as the infection spreads along the recognized fascial planes resulting in a widespread loco-regional disease process.

Fournier gangrene is a relatively uncommon condition and the true incidence of this disease is unknown. A meta-analysis was able to identify about 1726 cases from January 1950 to September 1999. ${ }^{1}$ Another study has reported an average of about 97 cases per year in USA during 1989-1998. ${ }^{2}$ Males were predominantly affected and $11 \%$ to $14 \%$ of the patients were reported to be females in local and international studies. ${ }^{3,4}$ The lethality of this disease has not been subsided despite the advancement in intensive care techniques and development of new generation of antibiot- ics. Attempts have been made to determine the prognostic indicators of outcome and one of the major advancements in this regard was Fournier's gangrene severity index by Laor et $\mathrm{al}^{5}$ as shown in Table I. The objective of this study was to evaluate the impact ${ }^{6}$ of incorporating the involved surface area (Figure I) ${ }^{7}$ and platelets count in improving the predictive value of Laor's severity index.

\section{PATIENTS AND METHODS}

The demographics, clinical presentation, concomitant morbidities, laboratory parameters, microorganisms, management and final outcome were analyzed for 15 patients. Out of these, the medical records of 12 patients with fournier's gangrene managed at the Aga Khan University Hospital, Karachi between 1990 and 1999 were reviewed retrospectively. The data of three patients with Fournier's gangrene managed at the Isra University Hospital, Hyderabad, Pakistan between 2000 and 2004 were collected and analyzed prospectively. The patients were categorized on the basis of 
outcome that is whether the patient survived or expired. The fournier's gangrene severity index score described by Laor et al was calculated for each patient. In this system, score is calculated on the basis of haematological as well as biochemical parameters along with haemodynamic stability and febrile status. These parameters are graded from "0" to " 4 " on the basis of deviation from normal. Then the modified severity index score (Table II) was calculated for each patient. In this new scoring system, the involved surface area and platelets count were also evaluated in addition to the parameters mentioned in the Laor's severity index. Later, the relationships of two scoring systems with outcome category were evaluated.

\section{RESULTS}

In all, there were 15 male patients with fournier's gangrene managed during the above mentioned period. Out of these 15 patients, 11 survived whereas 04 could not survive and so the mortality rate was about $27 \%$ in this series of patients. Mean age of the entire group was 48 years with the range of 24 to 69 years. The main presenting features were fever, swelling, foul smelling wound discharge and gangrenous skin etc. Most of the patients presented within the first week of initiation of symptoms. No significant difference of timing of presentation was observed between survival and dead groups. No significant difference in age groups was observed between survived and dead groups. About $73 \%$ of the patients were found to be having Diabetes mellitus. Other co-morbidities were urinary tract infection, hypertension and ischemic heart disease. No significant difference of comorbidities was observed between survived and dead groups. The commonly encountered micro-organisms were Eschericia coli, Pseudomonas aeruginosa, Staphylococcus aureus and candida etc. There was no significant difference in microorganisms between the two groups divided on the basis of outcome. The mean involved surface area of entire group was $4 \%$ with the range of $0.5 \%$ to $14 \%$. The mean surface area for survived group was $3.5 \%$ with the range of $0.5 \%$ to $8 \%$ whereas that for dead group was $5.5 \%$ with the range of $0.5 \%$ to $14 \%$. On the basis of Laor's fournier gangrene severity index, the mean score for survived group was 6 with the range of "2" to "10" whereas that for dead group was 11.5 with the range of "8" to "13". Taking "7" as cut-off point, all 9 patients with score of 7 or less survived whereas 4 out of 6 patients with score of more than 7 died (Table III). On the basis of modified severity index, the mean score for the survived group was 8.5 with the range of " 2 " to "12" whereas that for the dead group was 15 with the range of "14" to "17". Taking "12" as cut-off point, 11 patients with the score of 12 or less survived whereas all 4 patients with score of more than 12 died.

TABLE I: LAOR'S FOURNIER GANGRENE SEVERITY INDEX

\begin{tabular}{|c|c|c|c|c|c|c|c|c|c|}
\hline VARIABLE & +4 & +3 & +2 & +1 & 0 & +1 & +2 & +3 & +4 \\
\hline Temp: $\left({ }^{0} \mathrm{C}\right)$ & $>41$ & $39-40.9$ & - & $38.5-38.9$ & $36-38.4$ & $34-35.9$ & $32-33.9$ & $30-31.9$ & $<29.9$ \\
\hline Pulse rate & $>180$ & $140-179$ & $110-139$ & - & $70-109$ & - & $55-69$ & $40-54$ & $<39$ \\
\hline Respiratory rate (b/min) & $>50$ & $35-49$ & - & $25-34$ & $12-24$ & $10-11$ & $6-9$ & - & $<5$ \\
\hline Serum $\mathrm{Na}^{+}(\mathrm{mmol} / \mathrm{l})$ & $>180$ & $160-179$ & $155-159$ & $150-154$ & $130-149$ & - & $120-129$ & 111-119 & $<110$ \\
\hline Serum $\mathrm{K}^{+}(\mathrm{mmol} / \mathrm{l})$ & $>7$ & $6-6.9$ & - & $5.5-5.9$ & $3.5-5.4$ & $3-3.4$ & $2.5-2.9$ & - & $<2.5$ \\
\hline $\begin{array}{l}\text { Serum Creatinine } \\
\text { (mg/100ml) }\end{array}$ & $>3.5$ & $2-3.4$ & $1.5-1.9$ & - & $0.6-1.4$ & - & $<0.6$ & - & - \\
\hline Haematocrit (\%) & $>60$ & - & $50-59.9$ & $46-49.9$ & $30-45.9$ & - & $20-29.9$ & - & $<20$ \\
\hline $\begin{array}{l}\text { WBC } \\
\text { (total } / \mathrm{mm}^{3} \times 1000 \text { ) }\end{array}$ & $>40$ & - & $20-39.9$ & $15-19.9$ & 3-14.9 & - & $1-2.9$ & - & $<1$ \\
\hline $\begin{array}{l}\text { Serum Bicarbonate } \\
\text { (mmol/l) }\end{array}$ & $>52$ & $41-51.9$ & - & $32-40.9$ & $22-31.9$ & - & $18-21.9$ & $15-17.9$ & $<15$ \\
\hline
\end{tabular}


FIGURE I:

PERCENTAGE ALLOCATION OF BODY SURFACE AREA

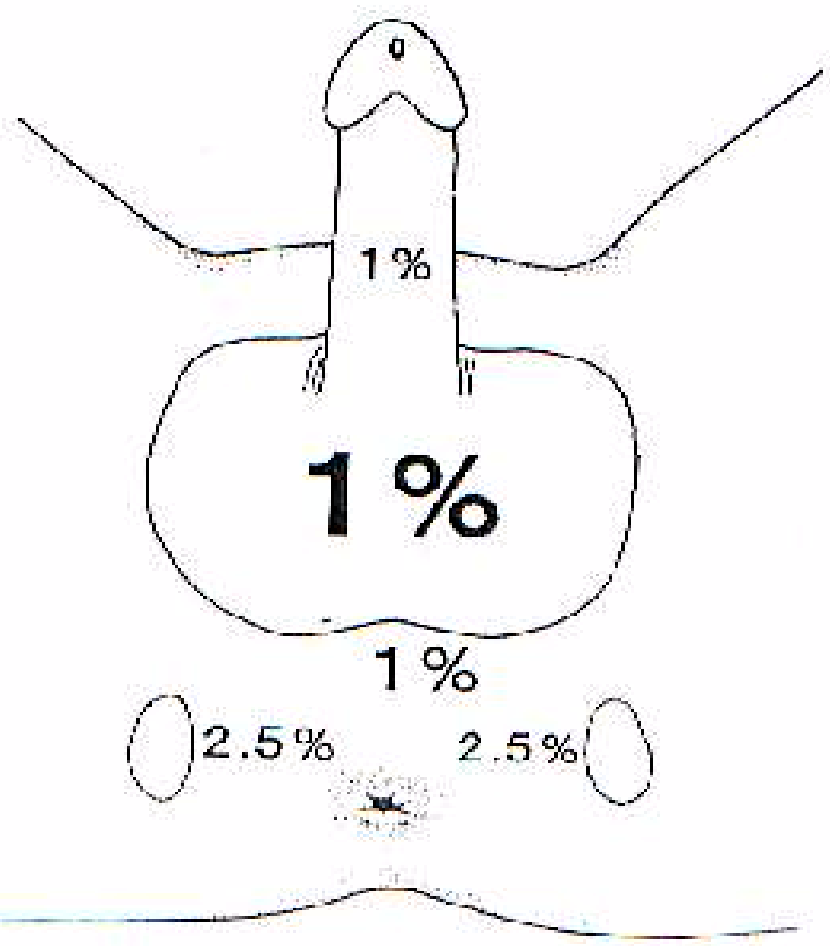

TABLE II:

MODIFIED SEVERITY INDEX OF FOURNIER'S GANGRENE

\begin{tabular}{|c|c|c|c|c|c|c|c|c|c|}
\hline VARIABLE & +4 & +3 & +2 & +1 & 0 & +1 & +2 & +3 & +4 \\
\hline Temp: $\left({ }^{0} \mathrm{C}\right)$ & $>41$ & $39-40.9$ & - & $38.5-38.9$ & $36-38.4$ & $34-35.9$ & $32-33.9$ & $30-31.9$ & $<29.9$ \\
\hline Pulse rate & $>180$ & $140-179$ & $110-139$ & - & $70-109$ & - & $55-69$ & $40-54$ & $<39$ \\
\hline Respiratory rate (b/min) & $>50$ & $35-49$ & - & $25-34$ & $12-24$ & $10-11$ & $6-9$ & - & $<5$ \\
\hline Serum $\mathrm{Na}^{+}(\mathrm{mmol} / \mathrm{l})$ & $>180$ & $160-179$ & $155-159$ & $150-154$ & $130-149$ & - & $120-129$ & $111-119$ & $<110$ \\
\hline Serum K ${ }^{+}$(mmol/l) & $>7$ & $6-6.9$ & - & $5.5-5.9$ & $3.5-5.4$ & $3-3.4$ & $2.5-2.9$ & - & $<2.5$ \\
\hline $\begin{array}{l}\text { Serum Creatinine } \\
(\mathrm{mg} / 100 \mathrm{ml})\end{array}$ & $>3.5$ & $2-3.4$ & $1.5-1.9$ & - & $0.6-1.4$ & - & $<0.6$ & - & - \\
\hline Haematocrit (\%) & $>60$ & - & $50-59.9$ & $46-49.9$ & $30-45.9$ & - & $20-29.9$ & - & $<20$ \\
\hline $\begin{array}{l}\text { WBC } \\
\text { (total } / \mathrm{mm}^{3} \times 1000 \text { ) }\end{array}$ & $>40$ & - & $20-39.9$ & $15-19.9$ & 3-14.9 & - & $1-2.9$ & - & $<1$ \\
\hline $\begin{array}{l}\text { Serum Bicarbonate } \\
(\mathrm{mmol} / \mathrm{l})\end{array}$ & $>52$ & $41-51.9$ & - & $32-40.9$ & $22-31.9$ & - & $18-21.9$ & $15-17.9$ & $<15$ \\
\hline $\begin{array}{l}\text { Platelets } \\
\left(\text { total } / \mathrm{mm}^{3} \times 1000\right)\end{array}$ & - & - & $>600$ & $451-600$ & $\begin{array}{l}150- \\
450\end{array}$ & $\begin{array}{l}121- \\
150\end{array}$ & $91-120$ & $40-90$ & $<40$ \\
\hline Surface area (\%) & $>3$ & $2.1-3$ & $1.1-2$ & $0.6-1$ & $<0.5$ & - & - & - & - \\
\hline
\end{tabular}


TABLE III:

COMPARISON OF LAOR'S AND MODIFIED SEVERITY INDICES IN THEIR RELATIONSHIPS WITH SURVIVAL

\begin{tabular}{|l|c|c|c|}
\hline $\begin{array}{l}\text { Scoring } \\
\text { index }\end{array}$ & Score & Survived & Dead \\
\hline $\begin{array}{l}\text { Laor's } \\
\text { Severity } \\
\text { Index }\end{array}$ & Less than "7" & 9 & 0 \\
\cline { 2 - 4 } & More than "7" & 2 & 4 \\
\hline $\begin{array}{l}\text { Modified } \\
\text { Severity } \\
\text { Index }\end{array}$ & Less than "12" & 11 & 0 \\
\cline { 2 - 4 } & More than "12" & 0 & 4 \\
\hline
\end{tabular}

\section{DISCUSSION}

A syndrome of unexplained gangrene of penis and scrotum without any obvious cause was initially described by Baurienne in 1764 and its eponymous name was given by Fournier in $1883 .{ }^{8}$ This is clinically defined as synergistic necrotizing fascitis of the genital, perineal or peri-rectal areas leading to thrombosis of small subcutaneous vessels probably due to the obliterative endarteritis as a result of the spread of microorganisms. It leads to the gangrene of overlying skin. Diabetes mellitus was found to be the most common concomitant morbidity in this study as well as the literature review. ${ }^{5,9,10}$ Other predisposing factors included urinary tract infection, perineal disease / surgery, local trauma, malignancy and other immunocompromised states. Urinary tract infection has been reported as the commonest co-morbidity in a local study. ${ }^{3}$ Hydrocele aspiration was also reported as the etiological factor in one of the local case reports. ${ }^{11}$ After adequate resuscitation and general stabilization of patient, the treatment of fournier's gangrene includes debridement, antibiotics, fecal/urinary diversion, hyperbaric oxygen ${ }^{12-14}$ and topical application of honey. ${ }^{15,16}$ Surgical debridement plays the key role ${ }^{17}$ and its aim is to remove all non-viable tissues, halt progression of infection and alleviate the systemic toxicity. The individual impact of various factors on survival has been analyzed in many studies. The systemic signs, laboratory parameters, number of surgical debridements and involved body surface area were the major factors studied. ${ }^{6,17,18}$ None of these factors were having statistical significance and did not appear to be practical in application individually. In order to formulate a clinically useful yardstick reflecting the physiological profile, Laor et al described the fournier's gangrene severity index. ${ }^{5}$ Later, the utility of this index was proved successfully in some of the studies. ${ }^{17,18}$ With the addition of involved body surface area and platelets count, the modified index was formulated. On applying Laor's index in this study, the patients having score of more than " 7 " had about $67 \%$ probability of death whereas the score of "7" or less was associated with $100 \%$ probability of survival. When the modified index was applied to same group of patients, it was seen that the score of more than "12" has $100 \%$ probability of death while the score of less than "12" is associated with $100 \%$ probability of survival. Although, the number of patients is quite small but the results demonstrate that the proposed modification of Laor's index has got better predictive value of outcome in the patients with fournier's gangrene in our circumstances. This is a useful guide for objective and simple quantification of prognosis but cannot be considered as the final parameter. This may also be used as a useful adjunct for cost-benefit analysis and for evaluating the therapeutic options. Its acceptance as a major yardstick for prognosis will be dependent upon its critical evaluation in the studies having larger sample size and achieving statistically significant results.

\section{REFERENCES}

1. Eke N. Fournier's gangrene: a review of 1726 cases. Br J Surg. 2000; 87(6): 718-28.

2. Gamagami RA, Mostafavi M, Gamagami A, Lazorthes F. Fournier's gangrene: an unusual presentation of rectal carcinoma. Am J Gastroenterol. 1998; 93(4):657-8.

3. Rajput MJ, Memon AS. Management of Fournier's gangrene: experience of two tertiary care hospitals in Sindh, Pakistan. J Liaquat Uni Med Health Sci. 2004; 3(2): 51-5.

4. Stephens BJ, Lathrop JC, Rice WT, Gruenberg JC. Fournier's gangrene: historic (1764-1978) versus contemporary (1979-1988) differences in etiology and clinical importance. Am Surg. 1993; 59 (3): 149-54.

5. Laor E, Palmer LS, Tolia BM, Reid RE and Winter $\mathrm{HI}$. Outcome prediction in patients with fournier's gangrene. J Urol. 1995; 154: 89-92.

6. Palmer LS, Winter HI, Tolia BM, Reid RE and Laor E. The limited impact of involved surface area and surgical debridement on survival in fournier's gangrene. J Urol. 1995;76: 208-212.

7. Curreri PW, Luterman A. Burns. In Schwartz SI, Shires GT, Spencer FC eds, Principles of Surgery. New York: McGraw-Hill, 1989: Pp. 285-306.

8. Smith GL, Bunker $\mathrm{CB}$, and Dinneen MD. Fournier's gangrene. Br J Urol. 1998; 81: 347355.

9. Korkut M, Icoz G, Dayangac M, Akgun E, Yeniay L, Erdogan O, et al. Outcome analysis in patients with Fournier's gangrene: report of 45 cases. Dis Col Rectum. 2003; 46(5): 649-52. 
10. Nisbet A, Thompson IM. Impact of diabetes mellitus on the presentation and outcome of Fournier's gangrene. Urology. 2002; 60(5): 775-9.

11. Ali MZ. Fournier's gangrene - A rare complication of hydrocoele aspiration. J Coll Physicians Surg Pak. 2004; 14(5): 304-5.

12. Baykal K, Albayrak S, Inal H, Elbuken E, Dundar $\mathrm{K}$, Onol Y. Fournier's disease: adjunctive hyperbaric oxygen therapy to classic therapy. Int J Urol. 1996; 3(2): 161-2.

13. Benizri E, Fabiani P, Migliori G, Chevallier D, Peyrottes A, Raucoules M, et al. Gangrene of the perineum. Urology. 1996; 47(6): 935-9.

14. Mindrup SR, Kealey GP, Fallon B. Hyperbaric oxygen for the treatment of Fournier's gangrene. $\mathrm{J}$
Urol. 2005; 173(6): 1975-7.

15. Hejase MJ, Simonin JE, Bihrle R, Coogan CL. Genital Fournier's gangrene: experience with 38 patients. Urology. 1996; 47(5): 734-9.

16. Gurdal M, Yucebas E, Tekin A, Beysel M, Aslan $\mathrm{R}$, Sengor F. Predisposing factors and treatment outcome in Fournier's gangrene. Analysis of 28 cases. Urol Int. 2003; 70(4): 286-90.

17. Chawla SN, Gallop C, Mydlo JH. Fournier's gangrene: an analysis of repeated surgical debridement. Eur Urol. 2003; 43(5): 572-5.

18. Yenivol CO, Suelozgen T, Arslan M, Ayder AR. Fournier's gangrene: experience with 25 patients and use of Fournier's gangrene severity index score. Urology. 2004; 64(2): 218-22.

AUTHOR AFFILIATION:

Dr. Abdul Samad (Corresponding Author)

Assistant Professor, Department of Surgery

Isra University Hospital Hyderabad, Sindh - Pakistan

E-mail: abdulsamad@email.com 